Research

\title{
Chronic exposure to MDMA (Ecstasy) elicits behavioral sensitization in rats but fails to induce cross-sensitization to other psychostimulants
}

\author{
Gunjan M Modi'1, Pamela B Yang1,2, Alan C Swann² and Nachum Dafny*1
}

Address: ${ }^{1}$ Department of Neurobiology and Anatomy, The University of Texas-Medical School at Houston, P.O. Box 20708, Houston, Texas 77225 , USA and ${ }^{2}$ Department of Psychiatry and Behavioral Sciences, The University of Texas-Medical School at Houston, P.O. Box 20708, Houston, Texas 77225, USA

Email: Gunjan M Modi - nachum.dafny@uth.tmc.edu; Pamela B Yang - pamela.b.yang@uth.tmc.edu; Alan C Swann - alan.c.swann@uth.tmc.edu; Nachum Dafny* - nachum.dafny@uth.tmc.edu

* Corresponding author

Published: 04 January 2006

Behavioral and Brain Functions 2006, 2:1 doi:10.1186/1744-908I-2-I
Received: 05 October 2005

Accepted: 04 January 2006

This article is available from: http://www.behavioralandbrainfunctions.com/content/2/I/I

(c) 2006 Modi et al; licensee BioMed Central Ltd.

This is an Open Access article distributed under the terms of the Creative Commons Attribution License (http://creativecommons.org/licenses/by/2.0), which permits unrestricted use, distribution, and reproduction in any medium, provided the original work is properly cited.

\begin{abstract}
Background: The recreational use of 3,4-methylenedioxymethamphetamine (MDMA, ecstasy) among adolescents and young adults has become increasingly prevalent in recent years. While evidence suggests that the long-term consequences of MDMA use include neurodegeneration to serotonergic and, possibly, dopaminergic pathways, little is known about susceptibility, such as behavioral sensitization, to MDMA.
\end{abstract}

Methods: The objectives of this study were to examine the dose-response characteristics of acute and chronic MDMA administration in rats and to determine whether MDMA elicits behavioral sensitization and whether it cross-sensitizes with amphetamine and methylphenidate. Adult male Sprague-Dawley rats were randomly divided into three MDMA dosage groups $(2.5 \mathrm{mg} / \mathrm{kg}, 5.0 \mathrm{mg} /$ $\mathrm{kg}$, and $10.0 \mathrm{mg} / \mathrm{kg}$ ) and a saline control group ( $\mathrm{N}=9 / \mathrm{group})$. All three MDMA groups were treated for six consecutive days, followed by a 5-day washout, and subsequently re-challenged with their respective doses of MDMA (day 13). Rats were then given an additional 25-day washout period, and re-challenged (day 38) with similar MDMA doses as before followed by either $0.6 \mathrm{mg} / \mathrm{kg}$ amphetamine or $2.5 \mathrm{mg} / \mathrm{kg}$ methylphenidate on the next day (day 39). Open-field locomotor activity was recorded using a computerized automated activity monitoring system.

Results: Acute injection of $2.5 \mathrm{mg} / \mathrm{kg}$ MDMA showed no significant difference in locomotor activity from rats given saline (control group), while animals receiving acute $5.0 \mathrm{mg} / \mathrm{kg}$ or $10.0 \mathrm{mg} /$ kg MDMA showed significant increases in locomotor activity. Rats treated chronically with $5.0 \mathrm{mg} /$ $\mathrm{kg}$ and $10.0 \mathrm{mg} / \mathrm{kg}$ MDMA doses exhibited an augmented response, i.e., behavioral sensitization, on experimental day 13 in at least one locomotor index. On experimental day 38, all three MDMA groups demonstrated sensitization to MDMA in at least one locomotor index. Amphetamine and methylphenidate administration to MDMA-sensitized animals did not elicit any significant change in locomotor activity compared to control animals.

Conclusion: MDMA sensitized to its own locomotor activating effects but did not elicit any crosssensitization with amphetamine or methylphenidate. 


\section{Background}

The recreational use of 3,4-methylenedioxymethamphetamine (MDMA, ecstasy) has become increasingly prevalent in recent years, with the highest incidence of use reported in adolescent and young-adult populations $[1,2]$. An estimated 6.4 million individuals have used MDMA, and its use has risen over the past decade [3]. This high rate of use, especially in younger human populations, is alarming since many animal studies have correlated MDMA use with the onset of lasting cognitive and behavioral deficits, including impairments in spatial memory and learning, increased anxiety-like behavior, and a weakened ability of the nervous system to react to stressful stimuli [4-12], while the addictive potential of MDMA, such as behavioral sensitization, remains poorly understood.

MDMA is a ring-substituted amphetamine derivative with a structural resemblance to the hallucinogen mescaline [13]. Physiological effects of MDMA use include hyperactivity [14-16], hyperthermia [17-20], and hyponatremia $[19,21]$. Pharmacologically, MDMA potently causes an acute rise in extracellular serotonin (5-HT), which is often behaviorally manifested as "5-HT syndrome" in rats $[8,9,14]$, characterized by low body posture, forepaw treading, and head-weaving. MDMA also causes an acute rise in extracellular dopamine (DA) levels $[22,23]$. The chronic administration of MDMA has been well-characterized for causing long-term persistent depletions in brain 5-HT levels, most likely due to the neurotoxic action of MDMA to 5-HT-releasing neurons $[7,24]$. In light of the increased incidence of MDMA use along with data suggesting neurotoxicity and long-term cognitive and behavioral deficits linked to its use, a good understanding of its potential to elicit dependence and abuse is paramount. Behavioral sensitization is one of the experimental markers to indicate the potential of a drug to produce dependence [25-27]. Behavioral sensitization is characterized by a progressively augmented response following repetitive administration of a drug. It is an accepted experimental model to verify for dependency on a drug [25-27]. Although the behavioral sensitization to psychostimulants such as cocaine [27], amphetamine [26,28,29], and methylphenidate [30-32] has been well characterized, the effects of repeated MDMA administration on locomotor activity are contradictory, with some studies suggesting that MDMA elicits behavioral sensitization $[18,27,33]$, and some showing that MDMA causes tolerance $[8,34]$ or neither [16].

Furthermore, behavioral cross-sensitization, which is the augmentation that occurs when pretreatment with one stimulant leads to greater sensitivity to another stimulant, has been established between psychostimulants, including between cocaine and amphetamine [35], methylphe-
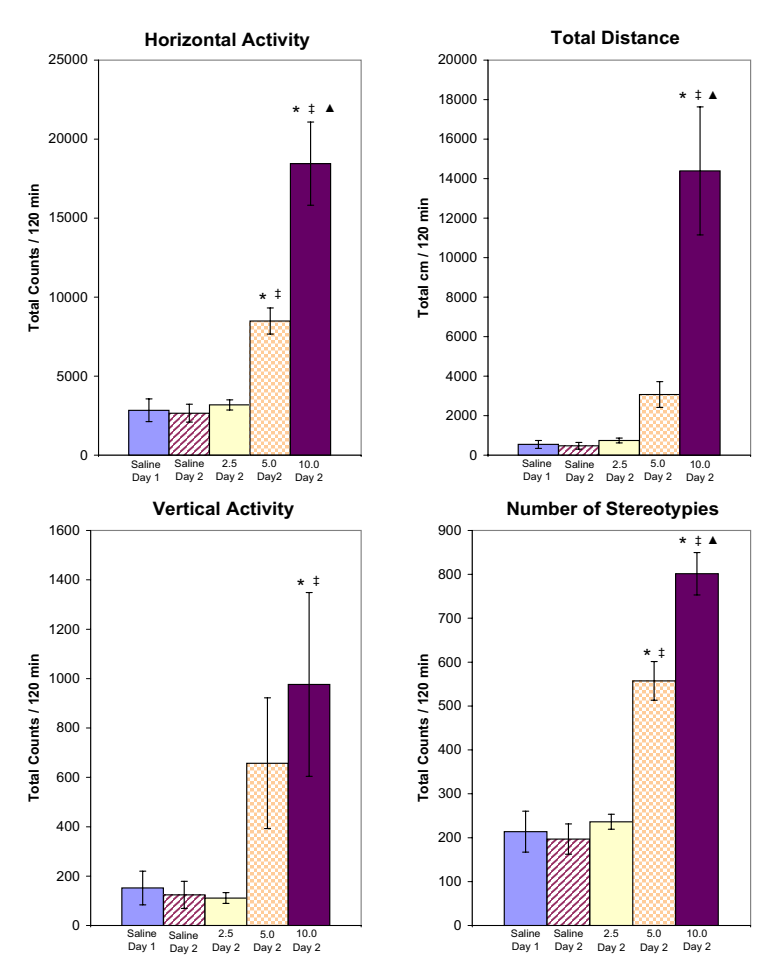

Figure I

summarizes the experiments measuring acute dose-response to MDMA (2.5, 5.0, and $10.0 \mathrm{mg} / \mathrm{kg}$, i.p.) for the HA, TD, VA, and NOS locomotor indices. The values are presented as the mean \pm S.E.M. *, $\ddagger$, and $\boldsymbol{\Delta}$ are for significant differences compared to experimental day 2 saline, $2.5 \mathrm{mg} / \mathrm{kg}$ MDMA, and $5.0 \mathrm{mg} / \mathrm{kg}$ MDMA, respectively $(p<0.05)$.

nidate and amphetamine [36], and methylphenidate and cocaine [37]. Kalivas et al. [27], Itzhak et al. [38], and Achat-Mendes et al. [39] reported that repeated MDMA treatment prior to cocaine resulted in an elevated behavioral response to cocaine. Pre-exposure to MDMA, therefore, may induce a cross-sensitized response to other psychostimulants such as amphetamine and methylphenidate.

The present study examined the acute and chronic doseresponse characteristics on locomotor activity in adult male Sprague-Dawley rats following MDMA and subsequently further re-challenged with amphetamine or methylphenidate. This was done to determine whether MDMA can elicit behavioral sensitization as well as to cross-sensitize with other psychostimulants. A sensitized and/or cross-sensitized response could prove invaluable in determining the potential of MDMA to elicit dependence/ addiction [40] and increased susceptibility to abuse of other addictive psychostimulants $[27,41]$. 


\section{Results \\ Controls}

In general, saline injections slightly increased locomotor activity during the first 10-minutes post-injection and returned to baseline and remained stable during the entire recording session. Figure 1 shows the activity following 2 consecutive saline injections (experimental days 1 and 2) and demonstrates that activity measured on these two days is similar. Therefore, any changes in locomotor activity recorded that deviate from saline group values obtained on experimental day 2 following MDMA treatment is recognized as an effect of the drug treatment. Previous time control experiments performed by this laboratory on rats given daily saline injections for 42 days have exhibited stable and similar baseline locomotor activity over the course of experiments [42].

\section{Dose-response effects of acute (single-injection) MDMA administration}

The general effects of MDMA were dose-dependent increases in locomotor activity across the indices measured. The lowest dose of MDMA $(2.5 \mathrm{mg} / \mathrm{kg}$ on experimental day 2), however, showed no effects on any of the locomotor indices studied versus animals given saline. Rats given $5.0 \mathrm{mg} / \mathrm{kg}$ MDMA on experimental day 2 (Fig. 1) showed trends of increases in HA, TD, VA and NOS, but only the increases in the HA and NOS indices were significant ( $\mathrm{p}<0.05$ ) compared to animals given $2.5 \mathrm{mg} / \mathrm{kg}$ or saline. Animals injected with $10.0 \mathrm{mg} / \mathrm{kg}$ MDMA showed a significant $(\mathrm{p}<0.05)$ increase in all four locomotor indices (HA, TD, VA, and NOS) when compared to the saline or to $2.5 \mathrm{mg} / \mathrm{kg}$ MDMA groups. Animals receiving 10.0 $\mathrm{mg} / \mathrm{kg}$ MDMA also had significantly ( $\mathrm{p}<0.05$ ) higher activity than animals receiving $5.0 \mathrm{mg} / \mathrm{kg}$ across the HA, TD, and NOS indices.

\section{Dose-response effects of chronic (multiple-injection) MDMA administration}

The total 2-h locomotor activity obtained on experimental days 1, 2, 7, 13 and 38 for the four indices is summarized in figure 2. Saline injections (Fig. 2) had no effect on locomotion and were similar for all the indices (HA, TD, VA, and NOS) studied. The effect of 6 consecutive daily MDMA exhibit similar locomotor activity, i.e. the initial response to MDMA on experimental day 2 was similar to experimental day 7. However, after 5 days of washout (experimental day 13), animals treated with $2.5 \mathrm{mg} / \mathrm{kg}$ (i.e., experimental day 13) MDMA showed a significant increase in locomotor activity across all four locomotor indices when compared with experimental day 2 . This significant increase in locomotion expresses behavioral sensitization. These same animals, however, showed no significant change in response to $2.5 \mathrm{mg} / \mathrm{kg}$, i.p, MDMA on experimental day 38; i.e., the repetitive treatment of $2.5 \mathrm{mg} / \mathrm{kg}$ MDMA elicited sensitization of a transient nature (Fig. 2). Animals treated with $5.0 \mathrm{mg} / \mathrm{kg}$ MDMA showed significant increases in locomotor activity on experimental day 13 across the HA, TD, and NOS indices. After 25 days of washout (on experimental day 38), animals re-challenged with $5.0 \mathrm{mg} / \mathrm{kg}$ exhibited sensitization across the HA, VA and NOS indices. The locomotor sensitization elicited by the $5.0 \mathrm{mg} / \mathrm{kg}$ dose thus persisted for a longer period of time than that of the $2.5 \mathrm{mg} / \mathrm{kg}$ dose. In animals injected with $10.0 \mathrm{mg} / \mathrm{kg}$ MDMA, the initial high dose elicited a robust increase in locomotor activity, but only the HA and VA indices exhibited sensitization on experimental day 13 and again (25 days later) on experimental day 38 (Figure 2).

The effects of chronic MDMA administration on animal weight and rate of weight gain were not significant compared to animals receiving saline (data not shown).

\section{Temporal dose-response characteristics of MDMA on locomotor activity}

Figures 3 and 4 summarize the temporal dose-response characteristics of the HA and NOS indices, on experimental day 2, 7, 13 and 38, respectively. To determine any significant change from baseline values due to drug action, we designated (prior to the experiment) that after drug treatment at least two consecutive 10-minute bins (i.e., significant changes over 20 minutes) with an activity count significantly different $(\mathrm{p}<0.05)$ from the corresponding 10-minute bins were needed in order to characterize the response to the drug as being significantly different from baseline. Based on this criterion, animals injected repeatedly with $2.5 \mathrm{mg} / \mathrm{kg}$ MDMA did not express significant change (on experimental days 7, 13, and 38) compared to experimental day 2 in HA (Fig. 3) or TD (data not shown) but showed a significantly increased response in the NOS index on experimental day 13 and experimental day 38 (Fig. 4). Animals injected with 5.0 $\mathrm{mg} / \mathrm{kg}$ MDMA showed a significant change in the HA and NOS indices in response to MDMA on experimental days 13 and 38, respectively (Figs. 3 and 4). Animals injected with repeated $10.0 \mathrm{mg} / \mathrm{kg}$ MDMA showed significant changes in HA (compared to experimental day 2) only in the HA index, seen on experimental days 7, 13, and 38 (Fig. 3). Sensitization was therefore observed and was persistent.

\section{Interaction between MDMA and amphetamine or methylphenidate}

On experimental day 39, six out of nine animals were treated with amphetamine while the remaining three were treated with $2.5 \mathrm{mg} / \mathrm{kg}$ methylphenidate (see Table 1 for experimental protocol). The locomotor activity in the saline group resulting from single amphetamine or single methylphenidate injection on experimental day 38 was used as control to compare with the locomotor activity 

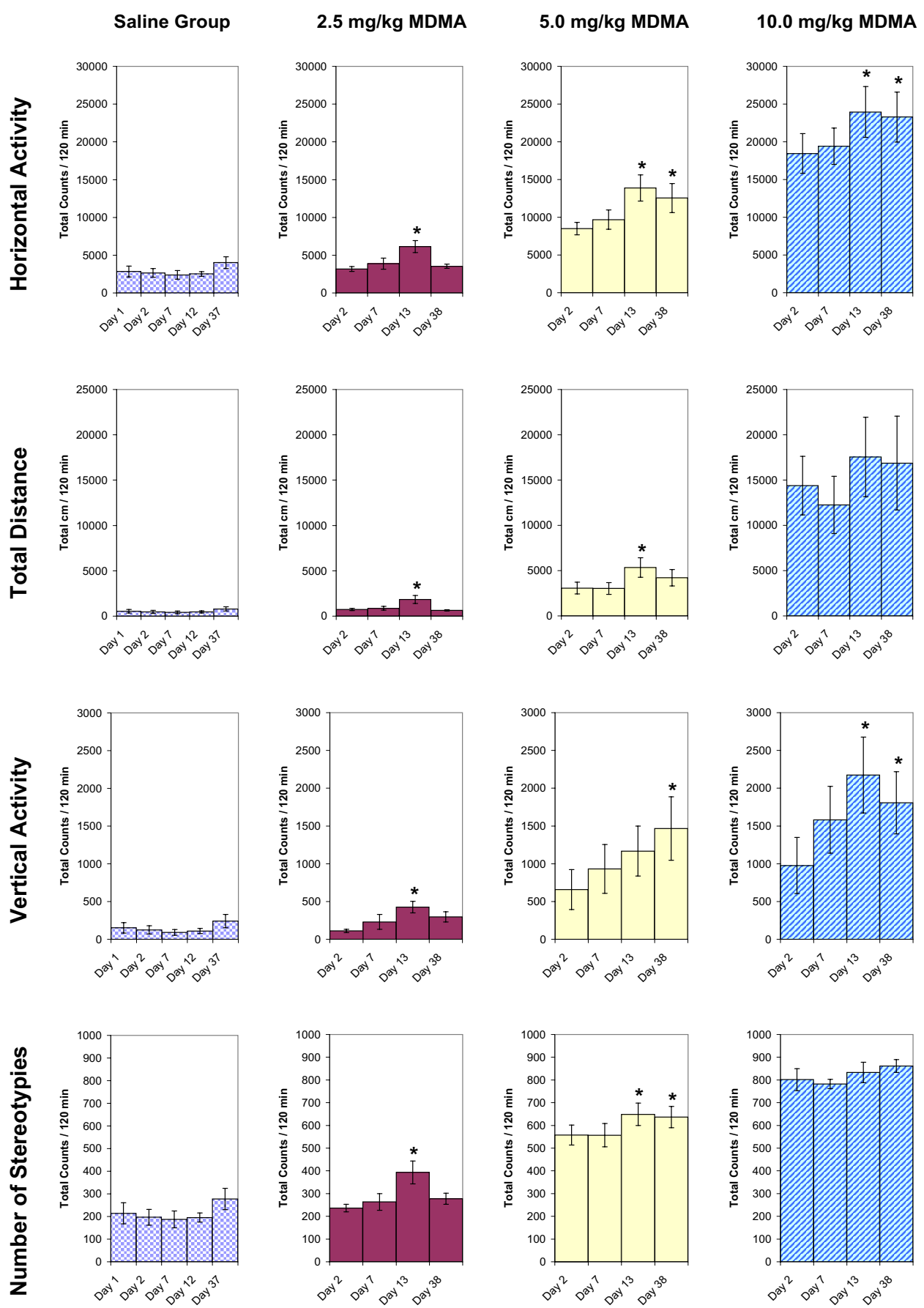

\section{Figure 2}

summarizes the experiments measuring the chronic dose-response to MDMA (2.5, 5.0, and $10.0 \mathrm{mg} / \mathrm{kg}$, i.p.) for the HA, TD, $V A$, and NOS locomotor indices. The values are presented as the mean \pm S.E.M. Significance is determined by comparing activity counts to Day 2 (saline day). *p $<0.05$. 
Sal group - Day 1

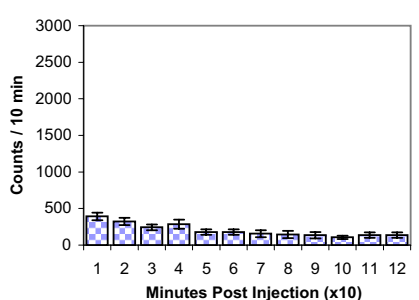

Sal group - Day 2

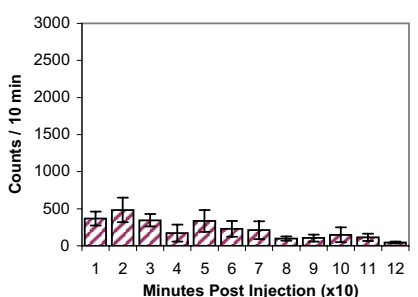

2.5 group - Day 2

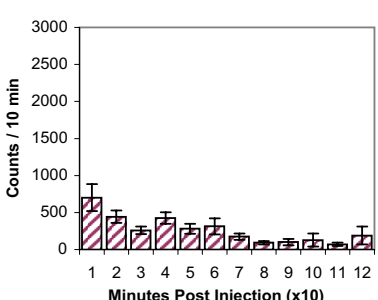

2.5 group - Day 7

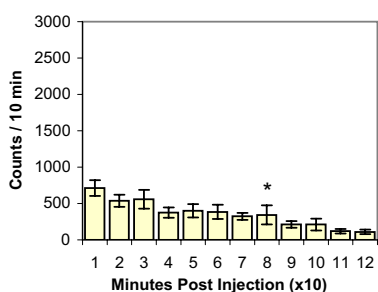

2.5 group - Day 13

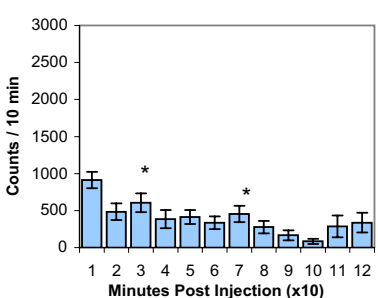

2.5 group - Day 38

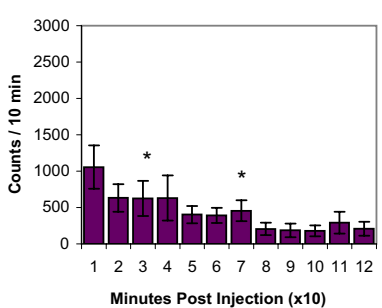

5.0 group - Day 2

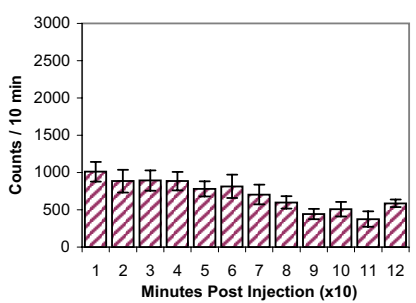

5.0 group - Day 7

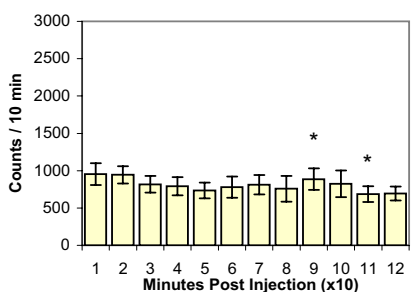

5.0 group - Day 13

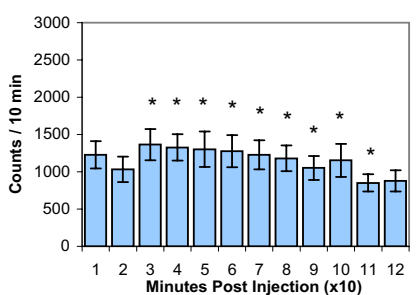

5.0 group - Day 38

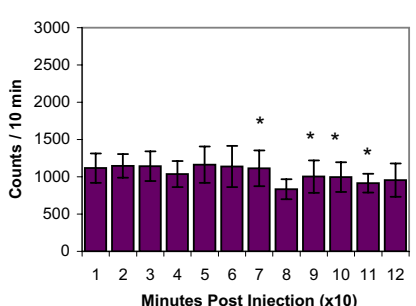

10.0 group - Day 2

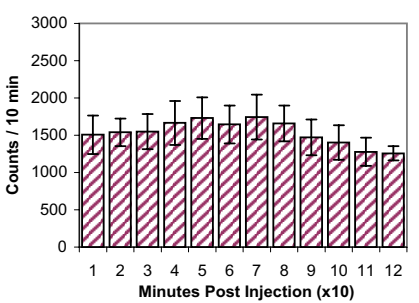

10.0 group - Day 7

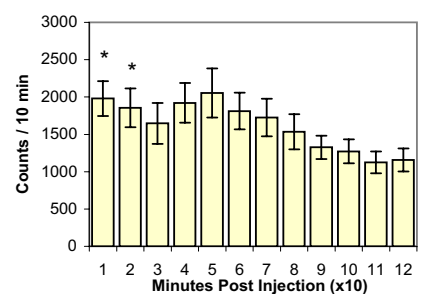

10.0 group - Day 13

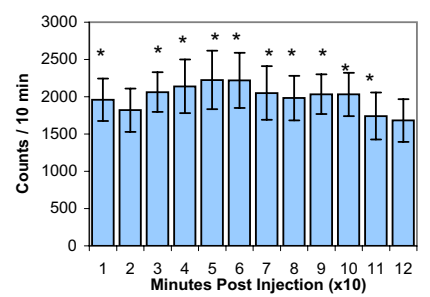

10.0 group - Day 38

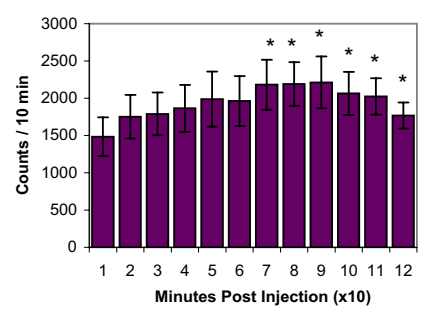

\section{Figure 3}

summarizes the temporal pattern of experiments measuring chronic dose-response to MDMA (2.5, 5.0 , and $10.0 \mathrm{mg} / \mathrm{kg}$, i.p.) for HA. The values for each 10 -minute bin are presented as the mean \pm S.E.M. Significance for each bin is determined by comparing activity counts to the same temporal bin on Day 2 (saline day). ${ }^{*} p<0.05$. 
Sal group - Day 1

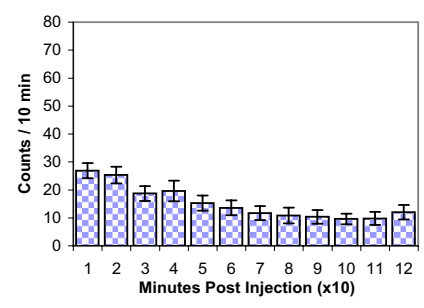

Sal group - Day 2

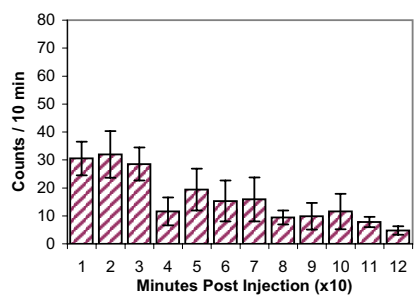

2.5 group - Day 2

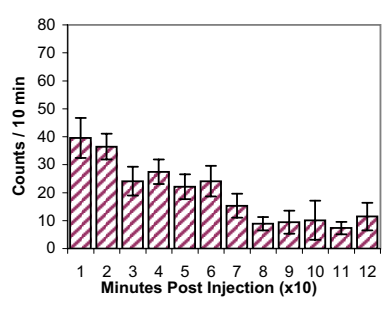

2.5 group - Day 7

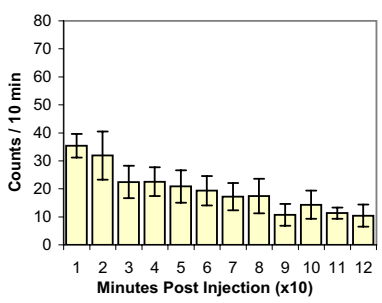

2.5 group - Day 13

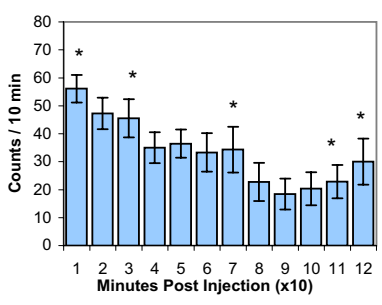

2.5 group - Day 38

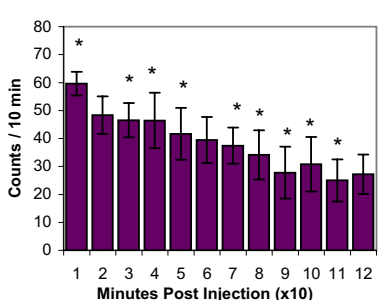

5.0 group - Day 2

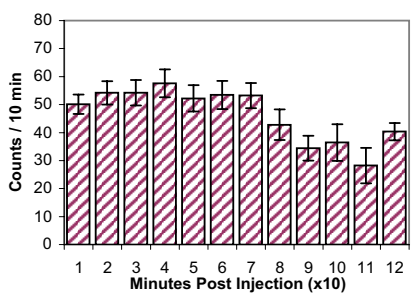

5.0 group - Day 7

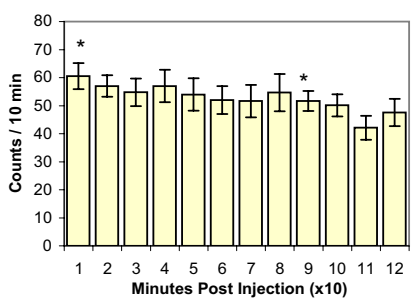

5.0 group - Day 13

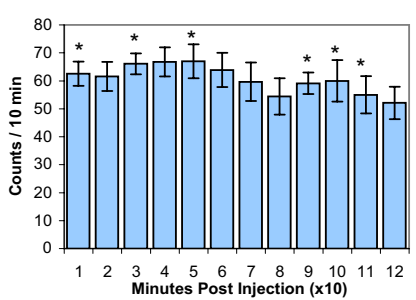

5.0 group - Day 38

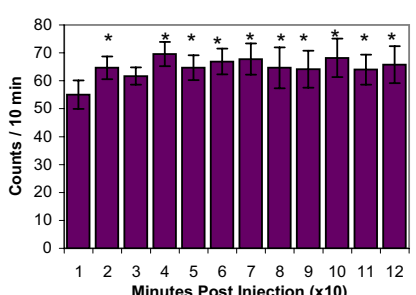

10.0 group - Day 2

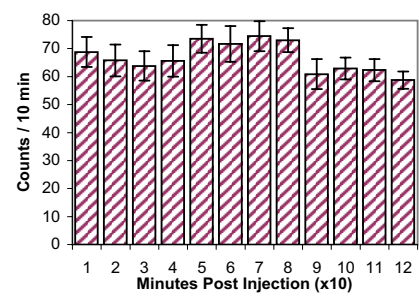

10.0 group - Day 7

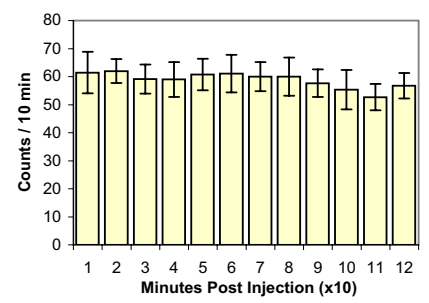

10.0 group - Day 13

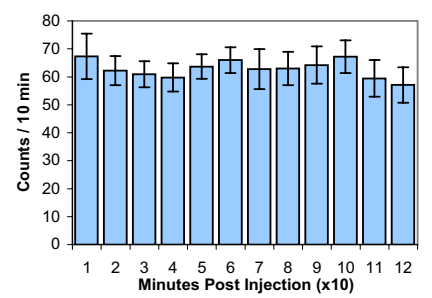

10.0 group - Day 38

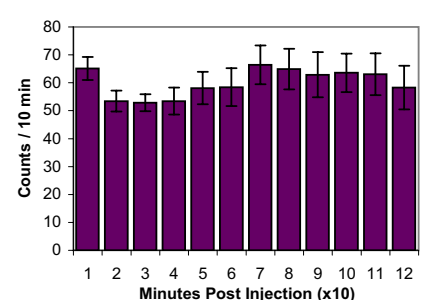

\section{Figure 4}

summarizes the temporal pattern of experiments measuring chronic dose-response to MDMA (2.5, 5.0 , and $10.0 \mathrm{mg} / \mathrm{kg}$, i.p.) for NOS. The values for each 10 -minute bin are presented as the mean \pm S.E.M. Significance for each bin is determined by comparing activity counts to the same temporal bin on Day 2 (saline day). ${ }^{*} p<0.05$. 
Table I: Schedule of Drug Treatment

\begin{tabular}{|c|c|c|c|c|c|c|c|c|}
\hline Experimental Day & Day I & Days 2-7 & Days 8-12 & Day 13 & Day 14 & Days 15-37 & Day 37 & Day 39 \\
\hline Sal Group ( $N=9)$ & Saline & Saline & Washout & 5.0 mg/kg MDMA & Amph & Washout & Saline & Amph/MPD \\
\hline 2.5 Group $(\mathrm{N}=9)$ & Saline & $2.5 \mathrm{mg} / \mathrm{kg}$ MDMA & Washout & 2.5 mg/kg MDMA & Amph & Washout & Saline & Amph/MPD \\
\hline 5.0 Group $(\mathrm{N}=9)$ & Saline & $5.0 \mathrm{mg} / \mathrm{kg}$ MDMA & Washout & $5.0 \mathrm{mg} / \mathrm{kg}$ MDMA & Amph & Washout & Saline & Amph/MPD \\
\hline 10.0 Group $(\mathrm{N}=9)$ & Saline & $10.0 \mathrm{mg} / \mathrm{kg}$ MDMA & Washout & $10.0 \mathrm{mg} / \mathrm{kg}$ MDMA & Amph & Washout & Saline & Amph/MPD \\
\hline
\end{tabular}

shows the schedule of drug treatment for the four experimental groups. Locomotor activity was recorded on experimental Days I-7, 12-14, 3739. The numbers in the first column (2.5, 5.0, and 10.0) refer to MDMA doses (i.p.). Amph $=0.6 \mathrm{mg} / \mathrm{kg}$ amphetamine. Amph/MPD: On experimental Day 39, animals in each group were given either $2.5 \mathrm{mg} / \mathrm{kg}$ methylphenidate $(\mathrm{N}=3 / \mathrm{group})$ or $0.6 \mathrm{mg} / \mathrm{kg}$ amphetamine $(\mathrm{N}=6 / \mathrm{group})$.

resulting from the same injections in the three MDMAtreatment groups at experimental day 39 . This was done to discern any potential interactions such as cross-tolerance or cross-sensitization between MDMA and amphetamine (Fig. 5) or MDMA and methylphenidate (Fig. 6). Figures 5 and 6 summarize this experiment and show that chronic MDMA treatment did not cause any significant changes to locomotor activity when animals were subsequently challenged with either amphetamine or methylphenidate.

\section{Discussion}

The drug MDMA has found increased prevalence in recreational use over the past decade. The question of whether or not it has the potential to elicit dependency is currently the subject of controversy. Several experimental paradigms used to investigate drug dependency include conditioned place preference $[15,23,39,43]$, self-administration [44-47], and behavioral sensitization $[14,18,27,38,48,49]$. Contradictory results are found whether chronic MDMA administration modulate these three models. Behavioral sensitization is one of the experimental marker that a drug elicits dependence $[25,27,36]$. The objective of the present study was to use doseresponse experiments in an open-field behavioral testing paradigm to investigate whether MDMA will elicit behavioral sensitization and whether chronic MDMA administration results in cross-sensitization to other psychostimulants, namely amphetamine and methylphenidate.

Three MDMA doses were selected for the dose-response study $(2.5,5.0$, and $10.0 \mathrm{mg} / \mathrm{kg})$. These doses were chosen based on similar doses used in other studies [14$16,18,38]$. Additionally, the MDMA doses administered also fall within the range of MDMA taken recreationally by humans [50]. The amphetamine $(0.6 \mathrm{mg} / \mathrm{kg})$ and methylphenidate $(2.5 \mathrm{mg} / \mathrm{kg})$ doses were used to assess cross-sensitization because these doses have been established in a previous study to individually elicit behavioral sensitization $[29,36]$.

In general, MDMA caused increases in locomotor activity, and these increases were dose-dependent i.e., increase locomotor activities with increasing the MDMA dose.
These findings are similar to those reported by other investigators $[43,47,50]$. It has been proposed that this locomotor hyperactivity following psychostimulant administration is a result of activation of DA-releasing neurons located primarily in the ventral tegmental area (VTA), nucleus accumbens (NAc), pre-frontal cortex (PFC), and other basal ganglia structures known collectively as the motive circuit $[51,52]$. However, locomotor hyperactivity induced by MDMA is markedly different from that induced by other psychostimulants such as amphetamine [53,54]. MDMA is believed to activate 5-HT pathways $[22,55]$ and co-activate dopaminergic pathways [50,55-57]. Dose-dependent increases in extracellular dopamine (DA) have been reported in animals following the first few hours post-MDMA administration [50]. Several hypotheses explain how DA is released after MDMA treatment: (1) MDMA interaction with DA uptake carrier causes release of DA [50], (2) the release of DA is the outcome of MDMA entry into DA nerve-ending tissue through diffusion [58], and (3) MDMA elicits DA release through activation of neurons by $5-\mathrm{HT}$ binding of $5-\mathrm{HT}_{2}$ receptor subtypes localized on DA releasing neurons. This last hypothesis is based on the observation that fluoxetine prevented the MDMA-induced release of DA [22,59].

Activation and subsequent reinforcement of primarily dopaminergic pathways in the motive circuit (VTA, NAc, PFC) and basal ganglia is believed to be responsible for the onset of behavioral sensitization due to repetitive (chronic) exposure of drugs, including classically addictive psychostimulants such as cocaine and amphetamine. This motive circuit regions is believed to mediate locomotor activity, and when reinforced, lead to progressive increases in DA and subsequent increase in locomotor activity, characterized as behavioral sensitization $[52,60$ 63]. This behavioral sensitization is used as a marker to indicate the property of a drug to have susceptibility for dependency [25-27].

The present findings indicate that MDMA does indeed elicit behavioral sensitization to its locomotor activating effects similar to other psychostimulants such as cocaine [52], amphetamine $[26,28]$, and methylphenidate $[30,31]$. The fact that MDMA sensitized to itself indicates 

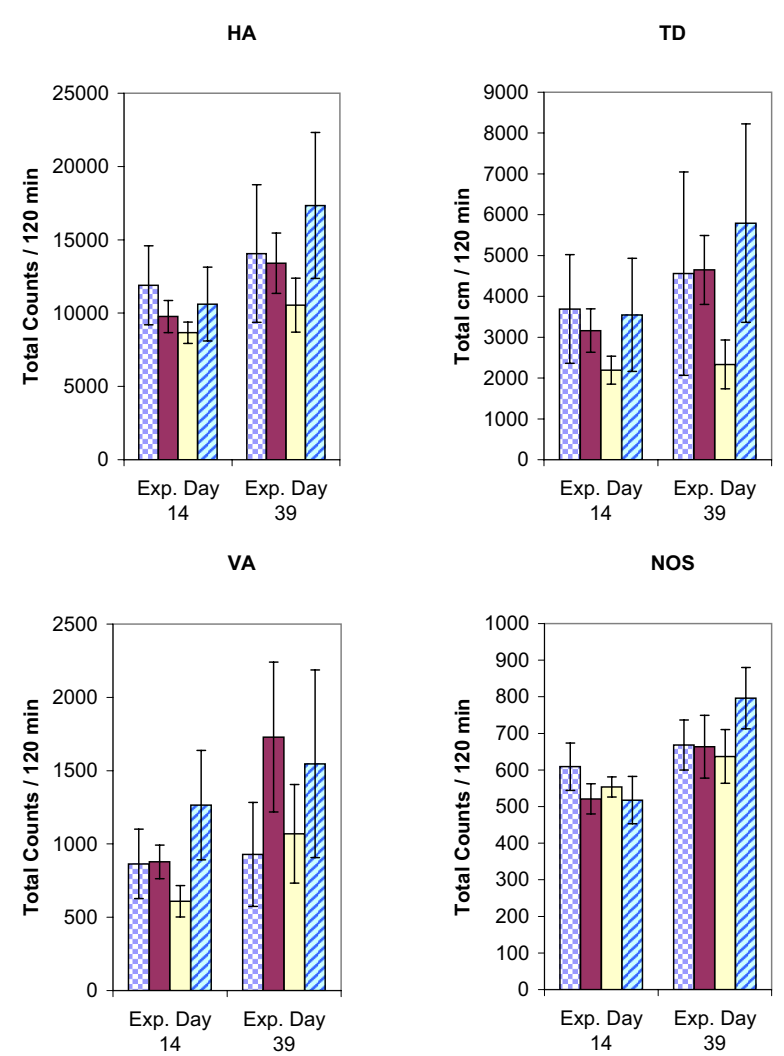

圆 sal group $\square 2.5$ group $\square 5$ group $\square 10$ group

\section{Figure 5}

summarizes the effects of a single amphetamine $(0.6 \mathrm{mg} / \mathrm{kg}$, i.p.) injection in animals treated chronically with MDMA or saline (see Table I) for the HA, TD, VA, and NOS locomotor indices on experimental days 14 and 39 , comparing activity counts of each MDMA treatment group to the saline group on the same experimental day. The values are presented as the mean \pm S.E.M. ${ }^{*} p<0.05$.

that MDMA may have the potential to elicit dependency. Behavioral sensitization following chronic treatment of MDMA using different experimental protocols was reported by some groups $[15,18,27,38]$, and was disputed by other observations [16]. This discrepancy in findings can be partially reconciled by accounting for differences in rat strain, sex, age, and various MDMA treatment protocols used. Investigators who studied only the horizontal activity reported that the drug elicited behavioral sensitization, while those who investigated different motor indices were not able to ascertain whether MDMA elicited sensitization. Specifically, as reported in other studies with psychostimulant sensitization, sensitization tends to be most robust in animals challenged after a sufficiently lengthy washout period following a repeated induction phase of pre-treatment $[27,30,31,36,52,63,64]$. Moreover, our study analyzed four different motor indices and showed sensitization in two of them and in the other two indices partial sensitization, which may explain this discrepancy, i.e., depending on the motor index used. Therefore, analyzing several locomotor indices is essential.

Cross-sensitization between psychostimulants such as between cocaine and amphetamine [65] and between amphetamine and methylphenidate [36] has been well characterized. Cross-sensitization between two psychostimulants could possibly indicate a similar mechanism in the neural adaptations mediating behavioral sensitization. In this study, animals previously treated with MDMA did not show a cross-sensitized response to amphetamine or methylphenidate. These results suggest that MDMA elicits sensitization by a neural pathway different to that reinforced by chronic amphetamine and methylphenidate. This is validated in cross- self-administration studies performed by Ratzenboeck et al [44]. Similarly, Cole et al. [66] reported that rats pre-treated with MDMA failed to elicit a conditioned place preference to d-amphetamine or cocaine. However, Fone et al. [9], Horan et al. [67], and Achat-Mendes et al. [39] found that rats repeatedly exposed to MDMA in adolescence exhibit an enhanced conditioned place preference to cocaine in adulthood. Morgan et al. [68] reported that repeated MDMA augments cocaine's ability to elevate extracellular DA levels in the rat's nucleus accumbens. Additionally, Fletcher et al., [41] established that repeated pre-exposure to high doses of MDMA facilitates acquisition of cocaine self-administration. Callaway and Geyer [34] reported that pre-treatment of rats with MDMA potentiated the activating effects of d-amphetamine. Inconsistencies in reports investigating cross-sensitization may be explained by the differences in methodologies including (but not limited to) the time and route of drug-administration, age and strain of the animals tested, and experimental paradigms. However, a possible explanation supporting the failure of MDMA to cross sensitize to other stimulants could be given by the presence of evidence suggesting that the primary course of action of MDMA is through 5-HT releasing neurons. While there are reports that MDMA directly impacts DA-releasing neurons, these effects are minor in relation to DA release by 5 -HT activation [27]. Blockade of $5-\mathrm{HT}_{2}$ receptor subtypes or serotonin transporters has been demonstrated to be effective in limiting acute DA release by MDMA $[22,69]$. The lack of a cross-sensitized response to amphetamine and methylphenidate indicates that MDMA may not increase the vulnerability to abuse of other psychostimulants.

\section{Conclusion}

The findings of this study are that (1) an acute dose of MDMA causes dose-dependent increases in locomotor 

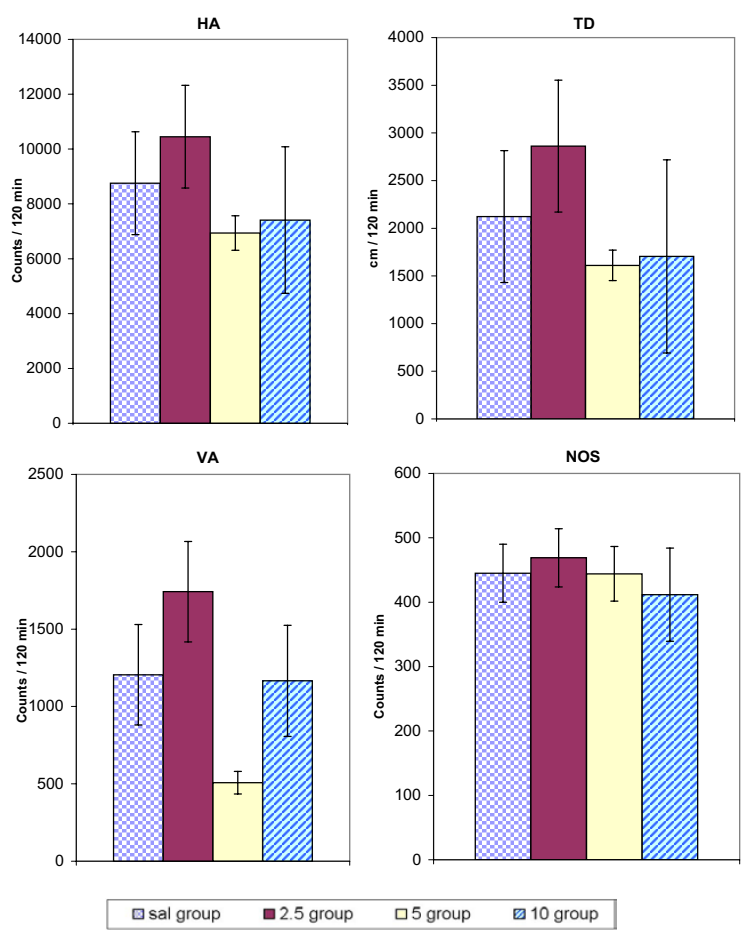

\section{Figure 6}

summarizes the effects of a single methylphenidate $(2.5 \mathrm{mg} /$ $\mathrm{kg}$, i.p.) injection in animals treated chronically with MDMA or saline (see Table I) for the HA, TD, VA, and NOS locomotor indices on experimental day 39, comparing activity counts of each MDMA treatment group to the saline group. The values are presented as the mean \pm S.E.M. ${ }^{*} p<0.05$.

activity; (2) chronic MDMA administration causes transient behavioral sensitization to a low dose $(2.5 \mathrm{mg} / \mathrm{kg})$ of MDMA and produces more persistant behavioral sensitization to the higher MPD doses (5.0 and $10.0 \mathrm{mg} / \mathrm{kg}$ ); (3) chronic MDMA administration did not elicit a cross-sensitized response to amphetamine or methylphenidate; and (4) chronic administration of MDMA did not interrupt animal growth with regard to weight.

\section{Materials and methods}

Thirty-six male Sprague Dawley rats (Harlan, Indianapolis, IN), weighing 200-240 g at the beginning of experiments, were housed in groups of four in Plexiglas cages in an animal housing facility. The facility was maintained on a 12-hour light/dark cycle (lights on at 07:00) with temperature at $21 \pm 2{ }^{\circ} \mathrm{C}$ and the relative humidity at $38 \%-$ $42 \%$. Water and food pellets were supplied ad libitum. Animals were handled daily in the housing facility for five days prior to experimental manipulation. All experiments were carried out in accordance with the National Institutes of Health Guide for the Care and Use of Laboratory Animals and approved by the University of Texas Center for Laboratory Animal Medicine and Care.

After five days of habituation, animals were taken to a testing room for daily experimentation. The testing room was maintained at the same environmental conditions as the animal housing facility. All experiments were conducted in the testing room between 09:00 and 15:00 h. Each animal was placed individually in a computerized automated activity test chamber that consists of an acrylic open-field box $(40.5 \times 40.5 \times 31.5 \mathrm{~cm})$ equipped with two levels of infrared photo-beam sensors located 6.0 and $12.5 \mathrm{~cm}$ above the floor of the box (AccuScan Instruments, Columbus, $\mathrm{OH}$ ). The system checked for interruptions of each infrared beam at a frequency of $100 \mathrm{~Hz}$. Interruption of any single beam resulted in the recording of an activity count. Simultaneous interruptions of two or more consecutive beams separated by at least one second were recorded as a movement score. This system has been previously described in detail $[29,30,32,36]$.

Locomotor activity counts were summed into 10-minute bins (12 bins per 120-minute session). These data were subsequently downloaded to an IBM-compatible computer through a Versamax analyzer (AccuScan Instruments, Columbus, $\mathrm{OH}$ ) and sorted into various locomotor indices for analysis. Four locomotor indices were analyzed: horizontal activity (HA), total distance (TD), vertical activity (VA), and number of stereotypies (NOS). The HA index measures the total number of beam interruptions that occurred in the bottom level of infrared beams during a given sample period; TD is a measure of the amount of forward ambulatory activity; VA measures the total number of beam interruptions that occurred in the upper level of infrared beams during a given sample period; and NOS measures the number of repetitive episodes with at least a 1-second interval before the beginning of another episode. The NOS index is used to assess the effect of drug treatment on general stereotypic behaviors such as sniffing, grooming, and other repetitive behaviors.

On each testing day, animals were placed in the open-field chambers and habituated for 30 minutes, after which injections were administered and subsequent locomotor activity was recorded for 120 minutes. On experimental day 1 (see Table I), all animals were injected with saline prior to recording activity. Beginning with experimental day 2, rats were divided into four experimental groups $(\mathrm{N}$ = 9/group) consisting of three MDMA-treatment groups $(2.5,5.0$, and $10.0 \mathrm{mg} / \mathrm{kg}$ ) and one control (saline) group. On experimental days 2-7, animals were treated in their testing cages with their respective doses of MDMA, and animals in the control group were given saline. All ani- 
mals were then given 5 days of washout (experimental days 8-12). On experimental day 13, animals were rechallenged with the same respective doses of MDMA given during the initial 6 days of treatment. Days 14-37, no injections were given, activity was not monitored, and animals were kept in the housing facility. On experimental day 38, animal activity was recorded again, following MDMA rechallenge as in experimental day 13 (Table 1 ). On experimental day 39, six animals challenged with 0.6 $\mathrm{mg} / \mathrm{kg}$ amphetamine and three animals with $2.5 \mathrm{mg} / \mathrm{kg}$, i.p., methylphenidate (Table 1). The drug treatment paradigm was adapted from similar psychostimulant doseresponse studies previously conducted by our laboratory $[28,29,31,32,36]$. Upon completion of daily locomotor activity recordings and injection, animals were returned to the housing facility.

All doses of $( \pm)$-3,4-methylenedioxymethamphetamine hydrochloride (MDMA; NIDA, Research Triangle Park, NC), d-amphetamine sulfate (Sigma-Aldrich, St. Louis, $\mathrm{MO}$ ), and methylphenidate hydrochloride (Mallinckrodt, St. Louis, MO) were calculated as free base and dissolved in $0.9 \%$ saline for administration. Injections were all administered intraperitoneally (i.p.) and equalized with $0.9 \%$ saline to a volume of $0.8 \mathrm{ml}$ so that the total volume of injection would not vary between animals.

The acute locomotor effects of MDMA were evaluated by comparing all three MDMA-treated groups on experimental day 2 against the saline-treated group on experimental day 1 . Sensitization to MDMA was determined by comparing activity scores from initial MDMA treatment (experimental day 2) with the activity scores recorded on the last day of MDMA maintenance (experimental day 7) and MDMA re-challenge days (experimental days 13 and 38). The presence of MDMA cross-sensitization to amphetamine or methylphenidate was determined between treatment groups by comparing the activity response to amphetamine challenge (experimental days 39) and methylphenidate challenge (experimental day 39 ) of the saline group (control group; animals pretreated with saline) with the activity response to amphetamine/methylphenidate challenge of the MDMA-treated groups. Observations within groups were analyzed using one-way Analysis of Variance (ANOVA: treatment days) and post-hoc Fischer's LSD method. Observations between groups were compared using the Student's paired t-test. Statistical significance was set at $p<0.05$ for all comparisons.

\section{Authors' contributions}

The experiment was conceived, developed, and reported collaboratively by all authors. GMM was primarily responsible for data collection and analysis.

\section{Acknowledgements}

This research was supported in part by the Pat Rutherford Chair in Psychiatry (ACS) and the National Research Service Award - DAI444I-0IAI (PBY). We wish to thank both the National Institute on Drug Abuse and Mallinckrodt, Inc. for their gifts of MDMA and methylphenidate, respectively.

\section{References}

I. Strote J, Lee JE, Wechsler H: Increasing MDMA use among college students: results of a national survey. J Adolesc Health 2002, 30(I):64-72.

2. Johnston LD, O'Malley PM, Bachman JG: Monitoring the Future national results on adolescent drug use: Overview of key findings, 2002. National Institutes on Drug Abuse 2003, NIH Publication No. 03-5374:.

3. Landry MJ: MDMA: a review of epidemiologic data. J Psychoactive Drugs 2002, 34(2): 163-169.

4. Broening HW, Morford LL, Inman-Wood SL, Fukumura M, Vorhees $\mathrm{CV}$ : 3,4-methylenedioxymethamphetamine (ecstasy)induced learning and memory impairments depend on the age of exposure during early development. J Neurosci 200I, 21 (9):3228-3235.

5. Williams MT, Morford LL, Wood SL, Rock SL, McCrea AE, Fukumura M, Wallace TL, Broening HW, Moran MS, Vorhees CV: Developmental 3,4-methylenedioxymethamphetamine (MDMA) impairs sequential and spatial but not cued learning independent of growth, litter effects or injection stress. Brain Res 2003, 968(I):89-10I.

6. Morley KC, Gallate JE, Hunt GE, Mallet PE, McGregor IS: Increased anxiety and impaired memory in rats 3 months after administration of 3,4-methylenedioxymethamphetamine ("ecstasy"). Eur J Pharmacol 200I, 433(I):91-99.

7. Sprague JE, Preston AS, Leifheit M, Woodside B: Hippocampal serotonergic damage induced by MDMA (ecstasy): effects on spatial learning. Physiol Behav 2003, 79(2):28I-287.

8. Marston HM, Reid ME, Lawrence JA, Olverman HJ, Butcher SP: Behavioural analysis of the acute and chronic effects of MDMA treatment in the rat. Psychopharmacology (Berl) 1999, I44(I):67-76.

9. Fone KC, Beckett SR, Topham IA, Swettenham J, Ball M, Maddocks L: Long-term changes in social interaction and reward following repeated MDMA administration to adolescent rats without accompanying serotonergic neurotoxicity. Psychopharmacology (Berl) 2002, I 59(4):437-444.

10. Gurtman CG, Morley KC, Li KM, Hunt GE, McGregor IS: Increased anxiety in rats after 3,4-methylenedioxymethamphetamine: association with serotonin depletion. Eur J Pharmacol 2002, 446(I-3):89-96.

II. Maldonado E, Navarro JF: MDMA ("ecstasy") exhibits an anxiogenic-like activity in social encounters between male mice. Pharmacol Res 200I, 44(I):27-3I.

12. Matuszewich L, Filon ME, Finn DA, Yamamoto BK: Altered forebrain neurotransmitter responses to immobilization stress following 3,4-methylenedioxymethamphetamine. Neuroscience 2002, I I O(I):41-48.

13. Kalant $\mathrm{H}$ : The pharmacology and toxicology of "ecstasy" (MDMA) and related drugs. Cmaj 200I, 165(7):917-928.

14. Spanos LJ, Yamamoto BK: Acute and subchronic effects of methylenedioxymethamphetamine [(+/-)MDMA] on locomotion and serotonin syndrome behavior in the rat. Pharmacol Biochem Behav 1989, 32(4):835-840.

15. Gold LH, Koob GF: MDMA produces stimulant-like conditioned locomotor activity. Psychopharmacology (Berl) 1989, 99(3):352-356.

16. McNamara MG, Kelly JP, Leonard BE: Some behavioural and neurochemical aspects of subacute $(+/-) 3,4-$ methylenedioxymethamphetamine administration in rats. Pharmacol Biochem Behav 1995, 52(3):479-484.

17. Dar KJ, McBrien ME: MDMA induced hyperthermia: report of a fatality and review of current therapy. Intensive Care Med 1996, 22(9):995-996.

18. Dafters RI: Hyperthermia following MDMA administration in rats: effects of ambient temperature, water consumption, and chronic dosing. Physiol Behav 1995, 58(5):877-882. 
19. Gowing LR, Henry-Edwards SM, Irvine RJ, Ali RL: The health effects of ecstasy: a literature review. Drug Alcohol Rev 2002, 2 I (I):53-63.

20. Gordon CJ, Watkinson WP, O'Callaghan JP, Miller DB: Effects of 3,4-methylenedioxymethamphetamine on autonomic thermoregulatory responses of the rat. Pharmacol Biochem Behav 1991, 38(2):339-344.

21. Traub SJ, Hoffman RS, Nelson LS: The "ecstasy" hangover: hyponatremia due to 3,4-methylenedioxymethamphetamine. J Urban Health 2002, 79(4):549-555.

22. Gudelsky GA, Nash JF: Carrier-mediated release of serotonin by 3,4-methylenedioxymethamphetamine: implications for serotonin-dopamine interactions. J Neurochem 1996, 66(I):243-249.

23. Marona-Lewicka D, Rhee GS, Sprague JE, Nichols DE: Reinforcing effects of certain serotonin-releasing amphetamine derivatives. Pharmacol Biochem Behav 1996, 53(I):99-105.

24. Shankaran M, Yamamoto BK, Gudelsky GA: Involvement of the serotonin transporter in the formation of hydroxyl radicals induced by 3,4-methylenedioxymethamphetamine. Eur J Pharmacol 1999, 385(2-3): I03-110.

25. Robinson TE, Berridge KC: The neural basis of drug craving: an incentive-sensitization theory of addiction. Brain Res Brain Res Rev 1993, I 8(3):247-29I.

26. Robinson TE, Becker JB: Enduring changes in brain and behavior produced by chronic amphetamine administration: a review and evaluation of animal models of amphetamine psychosis. Brain Res 1986, 396(2): I57-198.

27. Kalivas PW, Duffy P, White SR: MDMA elicits behavioral and neurochemical sensitization in rats. Neuropsychopharmacology 1998, I 8(6):469-479.

28. Gaytan O, Swann AC, Dafny N: Effects of amphetamine at the beginning of the light cycle on multiple indices of motor activity in the rat. Eur J Pharmacol 1996, 300( I-2): I-8.

29. Gaytan O, al-Rahim S, Swann A, Dafny N: Sensitization to locomotor effects of methylphenidate in the rat. Life Sci 1997, $6 I(8): P L I 0 I-7$.

30. Yang P, Singhal N, Modi G, Swann A, Dafny N: Effects of lithium chloride on induction and expression of methylphenidate sensitization. Eur J Pharmacol 200I, 426( I-2):65-72.

31. Nagilla R, Newland MC, Snyder J, Bronson ME: Effect of once weekly treatment with 3,4-methylenedioxymethamphetamine on schedule-controlled behavior in rats. Eur J Pharmacol I998, 358(I): I-8.

32. Callaway CW, Geyer MA: Tolerance and cross-tolerance to the activating effects of 3,4-methylenedioxymethamphetamine and a 5-hydroxytryptamine IB agonist. J Pharmacol Exp Ther 1992, 263(I):318-326.

33. Bonate PL, Swann A, Silverman PB: Context-dependent crosssensitization between cocaine and amphetamine. Life Sci 1997, 60(I):PLI-7.

34. Yang PB, Swann AC, Dafny N: Chronic pretreatment with methylphenidate induces cross-sensitization with amphetamine. Life Sci 2003, 73(22):2899-29I I.

35. Brandon CL, Marinelli M, Baker LK, White FJ: Enhanced reactivity and vulnerability to cocaine following methylphenidate treatment in adolescent rats. Neuropsychopharmacology 2001, 25(5):65I-66I.

36. Itzhak Y, Ali SF, Achat CN, Anderson KL: Relevance of MDMA ("ecstasy")-induced neurotoxicity to long-lasting psychomotor stimulation in mice. Psychopharmacology (Berl) 2003, 1 66(3):241-248.

37. Achat-Mendes C, Anderson KL, Itzhak Y: Methylphenidate and MDMA adolescent exposure in mice: long-lasting consequences on cocaine-induced reward and psychomotor stimulation in adulthood. Neuropharmacology 2003, 45(I): I06-I I5.

38. Segal DS, Geyer MA, Schuckit MA: Stimulant-induced psychosis: an evaluation of animal methods. Essays Neurochem Neuropharmacol 198I, 5:95-129.

39. Fletcher PJ, Robinson SR, Slippoy DL: Pre-exposure to (+/-)3,4methylenedioxy-methamphetamine (MDMA) facilitates acquisition of intravenous cocaine self-administration in rats. Neuropsychopharmacology 200I, 25(2): 195-203.

40. Bjork JM, Gaytan O, Patt N, Swann AC, Dafny N: Behavioral tolerance to and withdrawal from multiple fluoxetine administration. Int J Neurosci 1998, 93(3-4): I63-I79.
4I. Cole JC, Sumnall HR: The pre-clinical behavioural pharmacology of 3,4-methylenedioxymethamphetamine (MDMA). Neurosci Biobehav Rev 2003, 27(3): 199-217.

42. Ratzenboeck E, Saria A, Kriechbaum N, Zernig G: Reinforcing effects of MDMA ("ecstasy") in drug-naive and cocainetrained rats. Pharmacology 2001, 62(3): |38-|44.

43. Schenk S, Gittings D, Johnstone M, Daniela E: Development, maintenance and temporal pattern of self-administration maintained by ecstasy (MDMA) in rats. Psychopharmacology (Berl) 2003, I69(I):21-27.

44. Cornish JL, Shahnawaz Z, Thompson MR, Wong S, Morley KC, Hunt GE, McGregor IS: Heat increases 3,4-methylenedioxymethamphetamine self-administration and social effects in rats. Eur Pharmacol 2003, 482(1-3):339-34l.

45. Fletcher PJ, Korth KM, Robinson SR, Baker GB: Multiple 5-HT receptors are involved in the effects of acute MDMA treatment: studies on locomotor activity and responding for conditioned reinforcement. Psychopharmacology (Berl) 2002, | 62(3):282-29|.

46. Anderson $\mathrm{KL}$, Itzhak $\mathrm{Y}$ : Inhibition of neuronal nitric oxide synthase suppresses the maintenance but not the induction of psychomotor sensitization to MDMA ('Ecstasy') and p-chloroamphetamine in mice. Nitric Oxide 2003, 9(I):24-32.

47. McCreary AC, Bankson MG, Cunningham KA: Pharmacological studies of the acute and chronic effects of (+)-3, 4-methylenedioxymethamphetamine on locomotor activity: role of 5 hydroxytryptamine(IA) and 5-hydroxytryptamine(IB/ID) receptors. J Pharmacol Exp Ther 1999, 290(3):965-973.

48. Green AR, Mechan AO, Elliott JM, O'Shea E, Colado MI: The pharmacology and clinical pharmacology of 3,4-methylenedioxymethamphetamine (MDMA, "ecstasy"). Pharmacol Rev 2003, 55(3):463-508.

49. Pierce RC, Kalivas PW: A circuitry model of the expression of behavioral sensitization to amphetamine-like psychostimulants. Brain Res Brain Res Rev 1997, 25(2):192-216.

50. Kalivas PW, Duffy P: Time course of extracellular dopamine and behavioral sensitization to cocaine. I. Dopamine axon terminals. J Neurosci 1993, I 3(I):266-275.

51. Callaway CW, Wing LL, Geyer MA: Serotonin release contributes to the locomotor stimulant effects of 3,4-methylenedioxymethamphetamine in rats. J Pharmacol Exp Ther 1990 , 254(2):456-464.

52. Gold LH, Koob GF, Geyer MA: Stimulant and hallucinogenic behavioral profiles of 3,4-methylenedioxymethamphetamine and $\mathbf{N}$-ethyl-3,4-methylenedioxyamphetamine in rats. J Pharmacol Exp Ther 1988, 247(2):547-555.

53. Gough B, Ali SF, Slikker WJ, Holson RR: Acute effects of 3,4methylenedioxymethamphetamine (MDMA) on monoamines in rat caudate. Pharmacol Biochem Behav I991, 39(3):619-623.

54. Yamamoto BK, Spanos LJ: The acute effects of methylenedioxymethamphetamine on dopamine release in the awakebehaving rat. Eur J Pharmacol I988, I 48(2): I95-203.

55. Colado MI, Camarero J, Mechan AO, Sanchez V, Esteban B, Elliott JM, Green AR: A study of the mechanisms involved in the neurotoxic action of 3,4-methylenedioxymethamphetamine (MDMA, 'ecstasy') on dopamine neurones in mouse brain. $\mathrm{Br}$ J Pharmacol 200I, I34(8): I7| I-I723.

56. O'Shea E, Esteban B, Camarero J, Green AR, Colado MI: Effect of GBR 12909 and fluoxetine on the acute and long term changes induced by MDMA ('ecstasy') on the 5-HT and dopamine concentrations in mouse brain. Neuropharmacology 200I, 40(I):65-74

57. Koch S, Galloway MP: MDMA induced dopamine release in vivo: role of endogenous serotonin. I Neural Transm 1997, I 04(2-3): 135-146.

58. Giros B, Jaber M, Jones SR, Wightman RM, Caron MG: Hyperlocomotion and indifference to cocaine and amphetamine in mice lacking the dopamine transporter. Nature 1996, 379(6566):606-6I2.

59. Karler R, Calder LD, Thai LH, Bedingfield JB: The dopaminergic, glutamatergic, GABAergic bases for the action of amphetamine and cocaine. Brain Res 1995, 67 I(I): 100-104.

60. Pettit HO, Pan HT, Parsons LH, Justice JB]: Extracellular concentrations of cocaine and dopamine are enhanced during chronic cocaine administration. I Neurochem 1990, 55(3):798-804. 
61. Paulson PE, Robinson TE: Amphetamine-induced time-dependent sensitization of dopamine neurotransmission in the dorsal and ventral striatum: a microdialysis study in behaving rats. Synapse 1995, 19(I):56-65.

62. Paulson PE, Camp DM, Robinson TE: Time course of transient behavioral depression and persistent behavioral sensitization in relation to regional brain monoamine concentrations during amphetamine withdrawal in rats. Psychopharmacology (Berl) I99I, I03(4):480-492.

63. Wise RA, Leeb K: Psychomotor-stimulant sensitization: a unitary phenomenon? Behav Pharmacol I993, 4(4):339-349.

64. Cole JC, Sumnall HR, O'Shea E, Marsden CA: Effects of MDMA exposure on the conditioned place preference produced by other drugs of abuse. Psychopharmacology (Berl) 2003, 166(4):383-390.

65. Horan B, Gardner EL, Ashby CRJ: Enhancement of conditioned place preference response to cocaine in rats following subchronic administration of 3, 4-methylenedioxymethamphetamine (MDMA). Synapse 2000, 35(2):160-162.

66. Morgan AE, Horan B, Dewey SL, Ashby CRJ: Repeated administration of 3,4-methylenedioxymethamphetamine augments cocaine's action on dopamine in the nucleus accumbens: a microdialysis study. Eur J Pharmacol I997, 33 I(I):RI-3.

67. Yamamoto BK, Nash JF, Gudelsky GA: Modulation of methylenedioxymethamphetamine-induced striatal dopamine release by the interaction between serotonin and gamma-aminobutyric acid in the substantia nigra. J Pharmacol Exp Ther 1995, 273(3): 1063-1070.

68. Gaytan O, Yang P, Swann A, Dafny N: Diurnal differences in sensitization to methylphenidate. Brain Res 2000, 864(I):24-39.

69. Gaytan O, Swann A, Dafny N: Time-dependent differences in the rat's motor response to amphetamine. Pharmacol Biochem Behav 1998, 59(2):459-467.

\section{Publish with Bio Med Central and every scientist can read your work free of charge}

"BioMed Central will be the most significant development for disseminating the results of biomedical research in our lifetime. "

Sir Paul Nurse, Cancer Research UK

Your research papers will be:

- available free of charge to the entire biomedical community

- peer reviewed and published immediately upon acceptance

- cited in PubMed and archived on PubMed Central

- yours - you keep the copyright

Submit your manuscript here:

http://www.biomedcentral.com/info/publishing_adv.asp
BioMedcentral 